\author{
E. J. O. Kompanje \\ B. van der Hoven \\ J. Bakker
}

\section{Anticipation of distress after discontinuation of mechanical ventilation in the ICU at the end of life}

Received: 21 November 2007

Accepted: 20 February 2008

Published online: 31 May 2008

(C) The Author(s) 2008

E. J. O. Kompanje $(\varangle) \cdot$ B. van der Hoven · J. Bakker

Department of Intensive Care, Erasmus MC University Medical Center Rotterdam, P.O. Box 2040,

3000 CA Rotterdam, The Netherlands

e-mail: e.j.o.kompanje@erasmusmc.nl furosemide, administration of sedatives (for distress) and opioids (for pain and/or dyspnea) should be continued or started and methylprednisolone should be given in anticipation of stridor after extubation. Thirty minutes before extubation, Butylscopolamine should be given and methylprednisolone repeated. After this the patient should be extubated to secure a dying process as natural as possible with the lowest burden due to distress.

\section{Introduction}

A considerable number of patients admitted to the intensive care unit (ICU) die following withdrawal of mechanical ventilation [1-9]. Comfort of patients and relatives is essential in the withdrawal process [10]. Withdrawal of mechanical ventilation in patients beyond hope is often described as 'terminal weaning' [2, 3], a contradictory word that should be avoided [11]. Some ICU patients request discontinuation of ventilation themselves [12, 13], but most are unconscious. The decision is usually made by the physician and is based on a lack of correlation between the therapeutic effort and its effect [5]. Discontinuation of ventilation should be a process, especially in patients in which it can be predicted that spontaneous respiratory activity will be sustained for a significant period of time, requiring great preparation for adequate treatment of distressing symptoms. Few ICU scenes evoke greater consternation in relatives than the sight of a loved-one dying in apparent respiratory distress, gasping to catch adequate breath before death.

In one study, $33 \%$ of intensivists preferred a 'slower process of terminal withdrawal of ventilation' compared to $13 \%$ who preferred 'rapid extubation' [14]. Existing protocols are unsatisfactory due to lack of adequate 
preparation for treatment of all distressing symptoms $[15,16]$. Patients are rarely extubated before dying [46]. Following ventilation discontinuation without proper anticipatory preparation, excessive respiratory secretion is not uncommon, resulting in a 'death rattle' [17]. Post-extubation stridor can give rise to relatives' perception that the patient is choking and suffering while dying.

Care before withdrawal of mechanical ventilation should include:

1. Anticipation of pain, dyspnea associated respiratory distress (DARD), and terminal restlessness and treatment with adequate administration of opioids and sedatives.

2. Treatment of distressing symptoms when they occur despite anticipation.

3. Prevention of distressing symptoms such as excessive broncho-pulmonary secretion, 'death rattle', and postextubation stridor by means of timely withdrawal of the administration of parenteral fluids, pharmacological treatment of iatrogenic overhydration, and administration of methylprednisolone and anticholinergic agents.

Here we provide practical and ethical arguments regarding the need for anticipation of these symptoms.

\section{Administration of opioids}

Administration of opioids, sufficient to counteract pain and/or DARD should be established before ventilator withdrawal. Since many patients already receive benzodiazepines/opioids before the decision to withdraw treatment, the strategy is based on the existing dose and the prediction of the degree of DARD after withdrawal [14]. There is always the risk of under-medicating for pain, based on the assumption that 'no-pain' is associated with neuromuscular blockade during therapeutic ventilation $[18,19]$. Lying in bed, sedated and with severe organ failure, can cause severe pain in muscles and ligaments, especially in elderly patients. This is the main reason for the administration of opioids for pain in end-of-life care on the ICU. Sometimes opiods are proposed for use in 'sedation' [20]. Opioids are inadequate for sedation because they simply do not induce and maintain sleep [21], but can induce hallucinations, delirium, and restlessness [22]. One of the reasons to sedate a terminal patient is to relieve terminal stress. The dying 'organism' experiences stress due to organ and systemic failure, leading to irreversible destruction of homeostasis and physical death. An increase in endogenous cortisol is presumed to be a protective reflex against these fatal threats. It was hypothesized that if the extent of the terminal stress reaction was high, high-dose morphine administration would suppress a rise in cortisol levels. However, results indicate that cortisol levels are not suppressed by high-dose morphine [23]. Thus, administering morphine to moribund patients for relief of terminal stress is not effective. The only valid reason for morphine administration is the relief from (suspected) pain or the prevention and treatment of DARD, which is an observable corollary to subjective dyspnea. For patients and relatives, the sensation of breathlessness is one of the most terrifying symptoms during the dying process. Relatives fear the patient is undergoing excessive suffering due to suffocation. Opioids are often recommended agents for managing DARD [9, 24-26]. Several mechanisms may be responsible for the observed effects. Ventilatory insufficiency and failure at the end of life results from a number of causes including reduced respiratory neuromuscular capacity, increased load by airway obstruction, diminished lung and chest wall compliance, and suppression of the cerebral ventilatory drive in response to high $\mathrm{CO}_{2}$ levels. Several intercurrent stresses such as anxiety, fever, bronchoconstriction, or stridor may increase fatigue by further increasing drive, effort, and load. Augmented drive by increase in ventilatory effort can result in fatigue, which is clinically significant as shallow breathing occurs, leading to death [26]. Morphine reduces the work load of breathing, thereby protecting against premature death from fatigue [26].

Unfortunately, palliative administration of opioids is perceived as hastening of death [27]. Several studies have shown, however, that it does not effect survival in palliative [28-30] and ICU patients [2, 26, 31-33]. Doses exceeding the required amount necessary to achieve the desired effect of symptom relief should not be used. Much attention is given to physicians' intentions, but distinguishing between intent to provide palliative comfort or to hasten death is an impossible task. Indirect or hidden intentions cannot be completely determined. The administered dose and choice of medication in the individual patient, rather than intent, should be the determinant as to whether the physician is acting in accordance with normal standards. The often-mentioned risk of 'serious respiratory depression' is very rare $[21,34]$. Among 1,524 postoperative patients treated with systemic or neuraxial morphine, a respiratory rate of less than 10 breaths/min was recorded in only $18(1.2 \%)$ patients [35]. The term 'respiratory depression' has no clear definition [34], but in most cases it refers to low respiratory rate $(<10$ breaths/ $\mathrm{min}$ ), but are of no concern to dying patients, or at times, even desired. Death of an ICU patient is usually related to fatigue and dysfunction in multiple organs after withdrawal of ventilatory support and is not due to the administration of opioids.

Fentanyl is a potent analgesic [36], but should not be used for the prevention or treatment of DARD because it 
can increase muscle tone, leading to chest rigidity. This can induce breathlessness instead of treating it, especially in cachectic patients with weak muscles [37].

We recommend that morphine be started in order to prevent DARD, and that fentanyl be continued for pain, if that drug is already being used. Morphine could be started in patients with no or low tolerance, as an intravenous dose of $0.1 \mathrm{mg} / \mathrm{kg}$. Individuals with high tolerance require larger dosages. The pharmacokinetics of intravenous morphine show a peak effect within $30 \mathrm{~min}$ and this effect generally lasts for 1-2 h [44].

\section{Palliative sedation}

Palliative sedation is defined as deliberately inducing and maintaining deep sleep for the relief of intractable physical and mental symptoms in the last hours or days of life. In the ICU, palliative sedation is administered continuously until death. ICU patients, particularly those requiring mechanical ventilation, usually are already sedated such that they can tolerate ventilation and ICUassociated noxious stimuli. One of the goals of sedation before and after withdrawal of ventilation is anxiolysis. In ICU patients who are dying following withdrawal of ventilation, death occurs rapidly, even if they are not sedated. Therapeutic sedation thus becomes palliative sedation. Decreased consciousness is a means of achieving symptom relief in patients who are suspected to be dying or whose relatives are witnessing distressing symptoms. Seizures, tremors, confusion, anxiety, agitation, and hallucinations can also occur after benzodiazepine withdrawal. This is one of the reasons sedation should never be stopped at the end of life. There is also some evidence suggesting that sedatives, especially lorazepam, are independently associated with the development of delirium [38]. For this reason, we avoid the use of lorazepam as a sedative for symptom control. In some situations, midazolam can be effective when given as adjunct therapy to morphine in order to alleviate dyspnea [39]. There is no evidence that the use of benzodiazepines to treat discomfort after withdrawal of mechanical ventilation hastens death in palliative [40] or ICU patients [26, 31, 33]. Respiratory rates do not decrease to fatal levels when patients are given palliative sedation [35].

We recommend midazolam or propofol (Fig. 1). Midazolam has a rapid onset of action and is easily titrated. In patients with prolonged mechanical ventilation, sedation is problematic because tolerance can be an especially difficult problem in the palliative phase [41]. Propofol also has an antiemetic effect, but can be associated with severe myalgia and also cannot be given subcutaneously, which could be a problem in some cases.

\section{Neuromuscular blocking}

Some physicians choose to continue (or initiate) neuromuscular blocking agents after withdrawal of ventilation, while others believe that this constitutes deliberate termination of life and is therefore unethical [42]. One earlier study reports continuation of neuromuscular blocking in $9 \%$ of 33 patients [31]. In end-of-life care, in almost all patients, comfort can be achieved by adequate dosing of opioids and benzodiazepines or barbiturates without the use of neuromuscular blocking agents, which can and should be reversed within a short period. Neuromuscular blocking agents produce only the appearance of comfort [19] and deliberately terminate life as effect of the iatrogenic neuromuscular blockage in the absence of mechanical ventilation in patients. The agents are often continued or administered for prevention of gasping during the dying process. The half-life of these agents can often be hours and is frequently longer in patients with organ failure.

We believe there is no place for neuromuscular blocking agents in the treatment of dying patients after withdrawal of ventilation. Any existing therapeutic rationale is lost in the process of treatment withdrawal. It is only in patients who have received the agents in large doses, where neuromuscular function can only be partially restored due to organ failure and extreme fatigue, that an ethical challenge exists. Restoration of neuromuscular function can delay the actual withdrawal of mechanical ventilation beyond a point that is ethically defendable, producing more harm than benefit. These patients will not survive after withdrawal of ventilation and will die within minutes to hours, even without the influence of neuromuscular paralysis. The activity of any residual neuromuscular blocking agents can then not be seen as deliberate termination of life.

\section{Anticipation of excessive secretion}

Excessive broncho-pulmonary secretion is common in ICU patients after withdrawal of prolonged ventilation and can give rise to the development of a death rattle, which is often distressing for relatives to witness. In ICU patients, iatrogenic overhydration and prolonged mechanical ventilation are common causes of this problem. Withdrawal of mechanical ventilation should always be preceded by withdrawal of all artificial hydration and feeding. Furosemide should be given in cases of iatrogenic overhydration to reduce the risk of excessive broncho-pulmonary secretion and death rattle and to prevent airway obstruction and bronchospasm [43, 44].

The noise produced by oscillatory movements of secretions in the oropharynx, hypopharynx, and trachea in terminal patients is described as a 'death rattle'. Dying 
Fig. 1 Flow chart for withdrawal of mechanical ventilation
Decision to withdraw mechanical ventilation and subsequent removal of endotracheal tube based on medical criteria that further treatment is futile or disproportionate, or on patient's request to withdraw mechanical ventilation. The patient is allowed to die

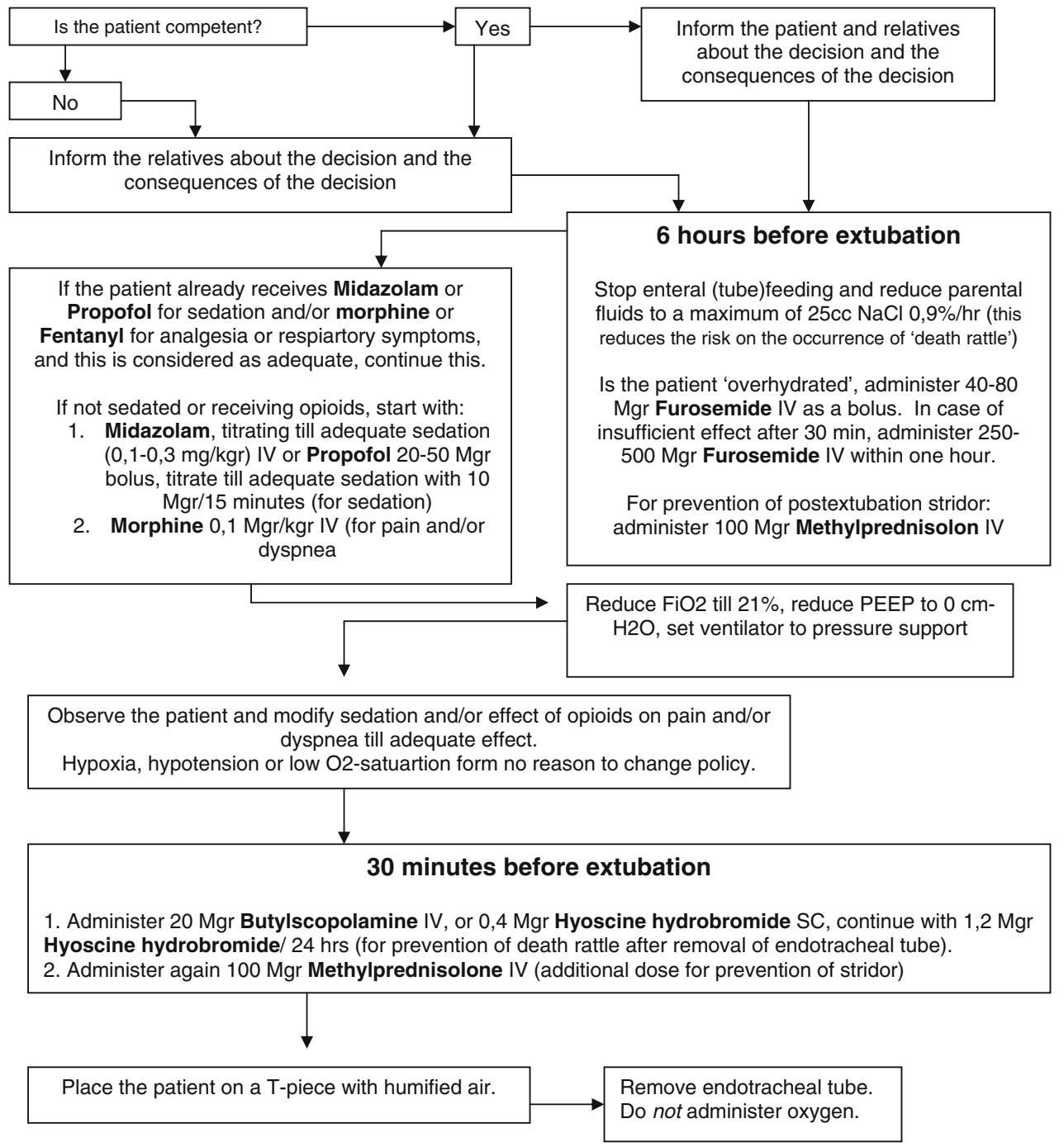

patients are usually too weak to expectorate or swallow the migrating secretions. Sputum usually only accumulates in these areas if there is significant impairment of the cough reflex, as in coma or near death. Death rattle is commonly reported in patients with neurological and pulmonary conditions during the last $48 \mathrm{~h}$ of life, with a prevalence of 40-50\% [17]. Observational studies report 41-92\% and larger prospective studies report an incidence of $44-56 \%$. The presence of a death rattle precedes death within $48 \mathrm{~h}$ in almost $75 \%$ of patients. Most patients appear to be unaware of their rattling respiration due to altered consciousness, and as long as they do not suffer, there is no ethical demand to treat it from the perspective of the patient. Only a few palliative care nurses felt that death rattle distressed the patient [45]. The primary aim of preventing or treating the noisy breathing is to reduce the distress of relatives of the patients and caregivers. We recommend administration of $20 \mathrm{mg}$ Butylscopolamine or $0.4 \mathrm{mg}$ Hyoscine hydrobromide $30 \mathrm{~min}$, before extubation to prevent a death rattle.

\section{Extubation and post-extubation stridor}

The decision to remove the endotracheal tube should be a secondary decision following discontinuation of ventilation. Extubation in the face of death (often called 
'terminal extubation') is the end of curative interventions for life support and symbolizes the start of passage to the end of life [46]. Post-extubation stridor is a potential source of distress, especially for the relatives and caregivers. The patient's appearance during post-extubation stridor is very disconcerting. Multi-center studies in Europe show that extubation preceding death is the leastused treatment, used only in 6-9\% of cases, during discontinuation of ventilation [47, 48]. Two-thirds of French caregivers felt that extubation should never be considered because it might worsen distress and may have a causal association with death. Fartoukh et al. [46] stated that the negative association with extubation stems from the fact that the family may interpret the ensuing noisy respiration or labored breaths as discomfort. They recommend nasal oxygen therapy immediately after extubation and in the case of dyspnea, corticosteroid treatment with a nebulizer. Increased sedation and analgesia were given in the case of discomfort (stridor and asphyxia) and scopolamine was given in accordance with the amount of respiratory secretions.

We recommend non-removal of the endotracheal tube only in exceptional cases because we believe post-extubation stridor and death rattle can be preempted by administering an intravenous injection of a single (or up to 4/day) dose of $100 \mathrm{mg}$ of methylprednisolone at least $6 \mathrm{~h}$ before extubation [49]. Studies found that after a single dose of $100 \mathrm{mg}$ of methylprednisolone, $88 \%$ of the patients showed no stridor and $93 \%$ showed no stridor after four doses. Stridor is the iatrogenic result of endotracheal intubation, which should be prevented and treated when it is distressing for the patient or their relatives. Gasping, however, is something that cannot be treated and in contrast with post-extubation stridor, is a normal sign of dying. Hypoxia serves as a 'natural sedative' at the end of life. For this reason we do object to routine administration of oxygen after extubation. This should be explained to the relatives.

\section{Relatives}

Before mechanical ventilation is withdrawn, the ICU staff should discuss with the relatives of the patient the intended withdrawal procedure, prepare for distressing symptoms, and the expected chance of survival [6]. The perceptions the relatives have regarding suffering and distress of the patient are important determinants for palliative care after withdrawal of life support. Explanation of the possible symptoms and of measures to counteract those symptoms may allow them to rest easier and reduce anxiety. ICU nurses prepare the relatives of patients mostly by describing physical sensations and symptoms [50]. Some patients will not die within minutes or hours after withdrawal of mechanical ventilation.
Some will even survive the ICU [5]. In our experience, most often, this concerns patients with severe cerebral catastrophes, but with intact brainstem and other organ functions. Physicians should be aware of this when informing the relatives about prognosis of survival.

\section{Recommended process}

For relatives, it is paramount that they see that their loved one die without significant distress and that dying should be as natural as can be. For this reason, we recommend a two-phase, 6-h period for the process of withdrawal of mechanical ventilation, taking the aforementioned aspects into consideration (Fig. 1). In the first phase, lasting from $6 \mathrm{~h}$ to $30 \mathrm{~min}$ before actual withdrawal of mechanical ventilation and removal of the endotracheal tube, the focus is on sedation, analgesia, prevention of DARD, post-extubation stridor, and excessive broncho-pulmonary secretions as the result of overhydration. In the second phase, $30 \mathrm{~min}$ before actual withdrawal of mechanical ventilation and removal of the endotracheal tube, the focus is on prevention of death rattle by means of medication. When this is followed, most patients will die without significant distress and 'naturally' without tubes and technology around the bed.

\section{Conclusion}

The actual phase of discontinuation of mechanical ventilation can be very short, but thoughtful anticipation of distressing symptoms takes more time. Given that the patient has serious respiratory or ventilatory insufficiency, multiple organ failure, extremely diseased lungs, or severe neurological dysfunction, withdrawal of mechanical ventilation and subsequent removal of an endotracheal tube often induces or hastens death. These actions do not kill the patient, but allow the patient's disease to complete its natural course. There is an ethical mandate to both anticipate and treat (iatrogenic) induced symptoms such as pain, DARD, anxiety, delirium, post-extubation stridor, and excessive broncho-pulmonary secretions resulting from overhydration. This makes the process of withdrawal of mechanical ventilation in ICU patients a thoughtful process, taking palliative actions instead of fast terminal actions.

Open Access This article is distributed under the terms of the Creative Commons Attribution Noncommercial License which permits any noncommercial use, distribution, and reproduction in any medium, provided the original author(s) and source are credited. 


\section{References}

1. Gilligan T, Raffin TA (1995) Rapid withdrawal of support. Chest 108:14071408

2. Campbell ML, Bizek KS, Thill M (1999) Patient responses during rapid terminal weaning from mechanical ventilation. Crit Care Med 27:73-77

3. Krishna G, Raffin TA (1999) Terminal weaning from mechanical ventilation. Crit Care Med 27:9-10

4. Diringer MN, Edwards DF, Aiyagari V (2001) Factors associated with withdrawal of mechanical ventilation in a neurology/neurosurgery intensive care unit. Crit Care Med 29:1792-1797

5. Cook D, Rocker G, Marshall J (2003) Withdrawal of mechanical ventilation in anticipation of death in the intensive care unit. NEJM 349:1123-1132

6. Kirchhoff KT, Anumandla PR, Foth KT (2004) Documentation of withdrawal of life support in adult patients in the intensive care unit. Am J Crit Care 13:328-334

7. Mahambrey T, Fowler R (2004) What factors are associated with decisions to withdraw mechanical ventilation in the intensive care unit? JAMC 170:466

8. Marr L, Weissman DE (2004) Withdrawal of ventilatory support from the dying adult patient. J Support Oncol 2:283-288

9. Rocker GM, Heyland DK, Cook DJ (2004) Most critically ill patients are perceived to die in comfort during withdrawal of life support: a Canadian multicentre study. Can J Anesth 51:623-630

10. Truog RD, Cist AFM, Brackett SE (2001) Recommendations for end-oflife care in the intensive care unit: the ethics committee of the society of critical care medicine. Crit Care Med 29:2332-2348

11. Apelgren KN (2000) "Terminal" wean is the wrong term. Crit Care Med 28:3576-3577

12. Edwards MJ, Tolle SW (1992) Disconnecting a ventilator at the request of a patient who knows he will then die: the doctor's anguish. Ann Intern Med 117:254-256

13. Kompanje EJO, De Beaufort ID, Bakker J (2007) Euthanasia in intensive care: a 56-yeat-old man with a pontine hemorhage resulting in a locked-in syndrome. Crit Care Med 35:24282430

14. Faber-Langendoen K (1994) The clinical management of dying patients receiving mechanical ventilation: a survey of physician practice. Chest 106:880-888
15. Rubenfeld GD, Crawford SW (2001) Principles and practice of withdrawing life-sustaining treatment in the ICU. In: Curtis JR, Rubenfeld GD (eds)

Managing death in the ICU: the transition from cure to comfort. Oxford University Press, New York, pp 127147

16. Von Gunten C, Weissman DE (2003) Symptom control for ventilator withdrawal in the dying patient. J Palliat Med 6:774-775

17. Kompanje EJO (2006) 'Death rattle' after withdrawal of mechanical ventilation: practical and ethical considerations. Intensive Crit Care Nurs 22:214-219

18. Loper KA, Butler S, Nessly M (1989) Paralyzed with pain: the need for education. Pain 37:315-316

19. Pigazzi A, Manfredi PL (2000) Case presentation: undertreatment of pain: a risk associated with neuromuscular blockade in the intensive care unit. J Pain Symptom Manage 19:154

20. Rietjens JA, Van Delden JJM, Van der Heide A (2006) Terminal sedation and euthanasia: a comparison of clinical practices. Arch Intern Med 166:749753

21. Walsh TD (1990) Prevention of opioid side effects. J Pain Symptom Manage 5:362-367

22. Kompanje EJO, Van Zuylen C, Van der Rijt C (2006) Morphine is not a sedative and does not shorten life. Arch Intern Med 166:2047-2048

23. Erkut ZA, Klooker T, Endert E (2004) Stress of dying is not suppressed by high-dose morphine or by dementia. Neuropsychopharmacology 29:152-157

24. Mosenthal AC, Lee KF (2002) Management of dyspnea at the end of life: relief for patients and surgeons. J Am Coll Surg 194:377-386

25. Campbell ML (2004) Terminal dyspnea and respiratory distress. Crit Care Clin 20:403-417

26. Edwards MJ (2005) Opioids and benzodiazepines appear paradoxically to delay inevitable death after ventilator withdrawal. J Palliat Care 21:299-302

27. Merrill JM, Dale A, Thornby JI (2000) Thanatophobia and opiophobia of hospice nurses compared with that of other caregivers. Am J Hosp Palliat Care 17:15-23

28. Bercovitch M, Adunsky A (2004) Patterns of high-dose morphine use in a home-care hospice servive. Cancer 101:1473-1477

29. Thorns A, Sykes N (1999) Opioid use in last week of life and implications for end-of-life decision making. Lancet 356:398-399
30. Morita T, Tsunoda J, Inoue S (2001) Effects of high dose opioids and sedatives on survival in terminally ill cancer patients. J Pain Symptom Manage 21:282-289

31. Wilson WC, Smedira NG, Fink C (1992) Ordering and administration of sedatives and analgesics during the withholding and withdrawal of life support from critically ill patients. JAMA 267:949-953

32. Daly BJ, Thomas D, Dyer MA (1995)

Procedures used in withdrawal of mechanical ventilation. Am J Crit Care 5:331-338

33. Chan JD, Treece PD, Engelberg RA (2004) Narcotic and benzodiazepine use after withdrawal of life support. Association with time of death? Chest 126:286-293

34. Ko S, Goldstein DH, VanDenKerkhof EG (2003) Definitions of 'respiratory depression' with intrathecal morphine postoperative analgesia: a review of the literature. Can J Anesth 7:679-688

35. Shapiro A, Zohar E, Zaslansky R (2005) The frequency and timing of respiratory depression in 1524 postoperative patients treated with systhemic or neuraxial morphine. J Clin Anesth 17:537-542

36. Stanley TH (2005) Fentanyl. J Pain Symptom Manage 29:S67-S71

37. Zylicz Z, van Rijn-Van der Plaat LL (2006) Fentanyl may increase breathlessness in a patient with motor neuron disease. J Pain Symptom Manage 32:199-200

38. Pandharipande P, Shintani A, Peterson J (2006) Lorazepam is an independent risk factor for transitioning to delirium in intensive care unit patients. Anesthesiology 104:21-26

39. Navigante AH, Cerchietti LCA, Castro MA (2006) Midazolam as adjunct therapy to morphine in the alleviation of severe dyspnea perception in patients with severe cancer. J Pain Symptom Manage 31:38-47

40. Mularski RA (2004) Pain management in the intensive care unit. Crit Care Clin 20:381-401

41. Cheng C, Roemer-Becuwe C, Pereira J (2002) When midazolam fails. J Pain Symptom Manage 23:256-265

42. Rushton C, Terry PB (1995) Neuromuscular blockade and ventilator withdrawal: ethical controversies. Am J Crit Care 4:112-115

43. Cavaliere F, Masieri S (2002) Furosemide protective effect agianst airway obstruction. Current Drug Targets 3:197-201 
44. Prandota J (2002) Furosemide: progress in understanding its diuretic, antiinflammatory, and bronchodilating mechanism of action, and use in the treatment of respiratory tract diseases. Am J Ther 9:317-328

45. Watts T, Jenkins K (1999) Palliative care nurses feelings about death rattle. J Clin Nurs 8:615-618
46. Fartoukh M, Brun-Buisson C, Lemaire $F(2005)$ Terminal extubation in 5 endof-life patients in intensive care units. Presse Med 34:495-501

47. Sprung CL, Cohen SL, Sjokvist P (2003) End of Life practices in European intensive care units: the Ethicus study. JAMA 290:790-797

48. Ferrand E, Robert R, Ingrand P (2001) Withholding and withdrawal of life support in intensive care units in France: a prospective survey. Lancet 357:9-14
49. Cheng KC, Hou CC, Huang HC (2006) Intravenous injection of methylprednisolone reduces the incidence of postextubation stridor in intensive care unit patients. Crit Care Med 34:1345-1350

50. Kirchhoff KT, Conradt KL, Anumandla PR (2003) ICU nurses preparation of families for death of patients following withdrawal of ventilator support. Appl Nurs Res 16:85-92 